Torin Monahan, Jennifer T. Mokos:

\title{
Sensing Environmental Danger in the City
}

\begin{abstract}
:
In this paper, we identify and discuss some of the ethical problems associated with digital sensors used to detect water contamination and air pollution in the United States. Such safety devices are often deployed unsystematically and with questionable efficacy, thereby structuring the life chances of people in unequal ways. Whereas most technological infrastructures are hidden from view - or at least from active awareness until they cease to function, those infrastructures meant to monitor and/or regulate largely "invisible" public health dangers resist public awareness even when they fail. Because such detection systems tend to individualize responsibility for reducing risk, the systems may normalize and perhaps exacerbate root problems of contamination and unequal exposure. One ethical challenge is to render such systems and their failures legible.
\end{abstract}

\section{Agenda:}

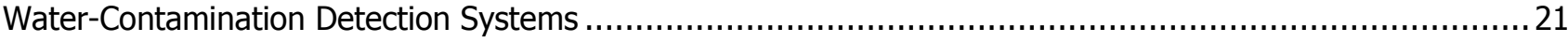

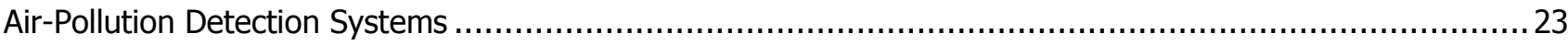

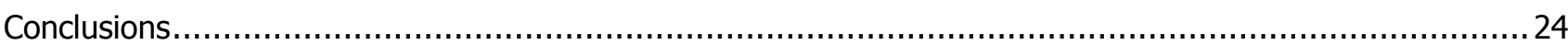

\section{Authors:}

Torin Monahan, Ph.D.

- Dept. of Human \& Organizational Development, Vanderbilt University, Peabody \#90, 230 Appleton Place, Nashville, TN 37203-5721, USA

- $\mathbf{- m}+1$ (615) 322-8732, $\square$ torin.monahan@vanderbilt.edu

- Relevant Publications:

- Surveillance in the Time of Insecurity (Rutgers University Press, 2010)

- Schools under Surveillance: Cultures of Control in Public Education (Rutgers University Press, 2010)

- Surveillance and Security: Technological Politics and Power in Everyday Life (Routledge, 2006)

Jennifer T. Mokos

- Dept. of Human \& Organizational Development, Vanderbilt University, Peabody \#90, 230 Appleton Place, Nashville, TN 37203-5721, USA

- $\square$ jennifer.mokos@vanderbilt.edu 
The health and wellbeing of urban denizens, as well as those residing in other areas, depend upon sophisticated technological infrastructures to monitor the environment for hazards and ensure the safety of basic utilities, such as water, gas, and electricity. While the management of such services is increasingly automated and informatized, judgments made about what the public's needs are and how they should met are often hidden in technical protocols that resist public awareness or scrutiny. Nonetheless, these vital systems, which include both public and private utilities, are political in that they differentially protect and endanger populations, often along lines of race and class. The deployment of information and communication technologies to manage public health infrastructures or basic utilities therefore invites critical inquiry into potential ethical problems being introduced and codified by digital systems for the provision of the public good.

In this paper, we analyze the use of electronic sensors to detect and mitigate the public's exposure to environmental toxins, with a specific focus on water contamination and air pollution in the United States. While U.S. law requires the collection and dissemination of water quality reports, and most cities actively monitor air quality and issue health warnings, the valence of such communications is toward risk management - rather than mitigation and individual responsibility for protection. Additionally, municipalities are more prone to use sensors to monitor water contaminants in largely populated urban regions that use reclaimed water that is "cleaned" at water treatment facilities. Less populated towns and rural areas that depend on well-water systems do not benefit from the same level of routine water monitoring and treatment and are subsequently exposed to harmful toxins at a much higher rate than their urban counterparts. With water and air quality alerts, people must be in a position to receive and process the warnings in a meaningful way. If one must work outdoors or utilize public transportation, for instance, he or she is more likely to be exposed to polluted air for longer periods of time and suffer associated health risks, such as asthma. Whether looking at systems to detect water contamination or air pollution, though, both appear to lead to unequal exposure for the most marginalized members of society: the urban and rural poor. The relatively affluent, on the other hand, can "choose" to install sophisticated water and air purifiers, have bottled drinking water delivered, or keep their families indoors on days with air quality alerts.
In the sections that follow, we identify and discuss some of the ethical problems associated with digital sensors used to detect water contamination and air pollution. Safe living environments are necessary for maintaining public health, and the introduction of such detector systems has the potential to minimize environmental dangers to which people are exposed. Nonetheless, safety devices are often deployed haphazardly and with questionable efficacy, effectively structuring the life chances of people in unequal ways. Whereas most technological infrastructures are hidden from view - or at least from active awareness - until they cease to function, ${ }^{1}$ those infrastructures meant to monitor and/or regulate largely "invisible" public health dangers resist public awareness even when they fail. One ethical challenge is to render such systems and their failures legible.

\section{Water-Contamination Detection Systems}

In the aftermath of $9 / 11$, concerns about potential terrorist threats to critical public infrastructures galvanized interest in a host of security systems and measures. Because public water supplies were seen as a likely target for future attacks, various industry and government reports called for better security of water facilities and reservoirs and automated systems to monitor water supplies in real time and trigger alerts should dangerous conditions be detected. ${ }^{2}$ The implementation of automated, real-time water-testing systems has been unsystematic though, mainly because of limited financial support from federal, state, and local governments and a reluctance on the part of policymakers to issue rules that would require utilities, many of which are private companies, to expend their own resources on such systems. ${ }^{3}$ One result of this is a situation where people continue to have different levels of protection based upon where they live, which companies serve them, and what protective measures they take on their own. While unequal exposure to risk is the key ethical issue about which we are concerned, the dangers of unsafe water in the U.S. were recognized long before the current wave of anxiety, and dangers are ever present even without terrorist attacks.

1 Bowker and Star 1999; Graham 2009

2 Tiemann 2004; American Water Works Association 2003; Campbell and Love 2008

3 Public Citizen 2004 
In the United States, a "Safe Drinking Water Act" was passed in 1974, and the Environmental Protection Agency (EPA) currently regulates the presence of 87 primary biological, chemical, and radiological contaminants in public water systems. ${ }^{4}$ Private water systems, including individual household wells are not regulated by EPA standards. ${ }^{5}$ Pollutants enter water sources through the natural weathering and erosion of harmful compounds from surrounding mineral deposits and geologic formations; however, most contaminants enter drinking water through anthropogenic means: discharge from petroleum refineries, metal refineries, chemical factories, and coal-burning factories; runoff from agricultural fertilizers, herbicides, and insecticides; leaching of septic tanks, gas storage tanks, and landfills. $^{6}$ Seven EPA regulated contaminants are products of disinfectants employed for the treatment of drinking water in order to control the presence of harmful microorganisms. ${ }^{7}$ Microorganisms typically enter drinking water through contact with human or animal waste. Minute viruses and Cryptosporidium bacteria evade detection and pass through filters causing serious health implications, particularly for immunocompromised individuals. ${ }^{8}$ According to recent data, "as many as 19 million Americans may become ill each year due to just the parasites, viruses, and bacteria in drinking water. Certain types of cancer - such as breast and prostate cancer have risen over the past 30 years, and research indicates they are likely tied to pollutants like those found in drinking water. ${ }^{\prime \prime 9}$ In spite of having federal legislation intended to ensure safe drinking water, since 2004 an estimated 20 percent of water utilities have violated the safety benchmarks established in this legislation. ${ }^{10}$

Chemical and radiological pollutants also have the potential to seriously impact upon public health. All radiological contaminants and many chemical contaminants regulated by the EPA are associated with an increased risk of cancer. Chemical contaminants are additionally associated with liver, kidney, and stomach problems, reproductive difficulties, nervous

4 U.S. Environmental Protection Agency 2009

5 U.S. Environmental Protection Agency 2003

6 Ritter et al. 2002

7 U.S. Environmental Protection Agency 2009

8 Robertson and Gjerde 2007

9 Duhigg 2009

10 Duhigg 2009 system damage, and circulatory system problems. ${ }^{11}$ Infants and children are particularly sensitive to lead and nitrate contamination. Lead enters drinking water through the corrosion of older, poorly maintained household pipes, thereby hindering children's physical and mental development, attention span, and learning abilities. ${ }^{12}$ Nitrates, typically found in fertilizer runoff, impede oxygen transport by hemoglobin in infants less than six months of age, causing serious illness ("blue baby syndrome") and potentially death. ${ }^{13}$ Rapid detection and notification is of vital importance to the prevention and mitigation of these serious health risks associated with acute and long-term exposure to biological, chemical, and radiological contaminants in drinking water.

During "contamination events," alerting systems communicate vital time-sensitive information but typically not very rapidly or effectively. Public notification of violations is often significantly delayed. Contamination events deemed to have the most serious health effects due to acute exposure must be reported within 24 hours, while all other violations must be reported within one year of the violation. ${ }^{14}$ Passive distribution of alerts places the responsibility for receiving information upon individuals and families, while national monitoring protocols are often not sufficient to identify critical instances of contamination.

Sensors that electronically detect environmental pollutants in drinking water provide water utilities with more frequent monitoring capabilities, increasing the potential for mitigation in response to contamination events. Biological sensors, used for rapid first-order detection of contamination, detect changes in abundance of bioluminescent bacteria within the sensor in response to water toxicity levels, while chemical sensors can ascertain levels of pollutants like arsenic and chlorine directly from the water column. ${ }^{15}$ When deployed at key locations, these online sensors have the advantage of continually sampling water for potential dangers. ${ }^{16}$ Monitoring data are sent to computer systems through radio or telephone lines at pre-determined intervals. Criteria levels programmed into monitoring software

11 Ritter et al. 2002

12 Miranda et al. 2009

13 Knobeloch 2000

14 U.S. Environmental Protection Agency 2003

15 Rodriguez-Mozaz, Lopez de Alda, and Barcelo 2006

16 Rodriguez-Mozaz, Lopez de Alda, and Barcelo 2006 
automate alerts to system operators. Real-time monitoring and automated alarms notify operators almost immediately when violations in water security occur, mitigating reliance on infrequent sampling protocols, which have the potential to miss shortterm time-sensitive breaches in water quality. Creation of a longitudinal database of water quality information allows for analysis of historical trends that is not typically possible due to the human investment required with more traditional sampling techniques. However, utilization of electronic sensors is not standardized and monitoring of water quality beyond EPA and state regulations is not required. While the EPA sets minimum monitoring requirements for each of the primary contaminants, and states can set more stringent requirements for testing frequencies, ${ }^{17}$ implementation of monitoring protocols and technologies for EPA-regulated pollutants in drinking water is mostly the responsibility of individual water utilities.

Although automated systems have the potential to detect water pollutants rapidly and alert people to their presence, the systems are not deployed systematically, public alerts are delayed and infrequent even when events do occur, and unequal exposure to toxins continues, thereby extending a legacy of environmental racism in the U.S. Especially in rural areas, people often gain access to water from private household wells, which are not regulated by EPA standards ${ }^{18}$ and where responsibility for monitoring is borne solely by individuals, many of whom are poor and placed at great risk when environmental accidents occur. ${ }^{19}$ Smaller public water utilities, which each serve up to 20,000 residents, are also guilty of the most violations of the Safe Drinking Water Act in the U.S. ${ }^{20}$ Additionally, there are currently 1,270 EPA-identified "Superfund" sites in the U.S., which are areas officially recognized as being in need of remediation because of toxins. ${ }^{21}$ Such sites are scattered throughout the country, including in largely populated cities where water treatment facilities are known to fail periodically, but that information is seldom disclosed to residents. Thus, people are expected to "responsibilize" to gain awareness of existing dangers or threats and mitigate their own (potential) exposure either by moving to areas thought to be safer or by purchasing

17 U.S. Environmental Protection Agency 2003

18 U.S. Environmental Protection Agency 2003

19 Guarino 2008

20 Duhigg 2009

21 http://www.epa.gov/superfund/sites/npl/index.htm home water-testing kits, bottled drinking water, reverse osmosis systems, shower filter systems, and so on. Automated water security systems could be thought of as possessing a valence for protecting the public good; in this neoliberal era, it is not surprising that they have not been adopted in any widespread way and have not significantly corrected environmental inequalities.

\section{Air-Pollution Detection Systems}

Individual exposures to airborne contaminants operate over multiple spatial and temporal scales.

Releases of chemicals and particulates from sources such as engine exhaust, power plant emissions, smokestack releases, and debris from construction sites and unpaved roads directly diminish local ambient air quality. Inhalation of these toxic materials exposes people to multiple respiratory and cardiovascular diseases, including chronic bronchitis, emphysema, asthma, lung cancer, heart attack, and stroke. ${ }^{22}$ Children, people with already existing lung disease, and older adults are particularly sensitive to high levels of air pollution.

The risk of exposure to high amounts of certain air pollutants varies with daily and seasonal variations in temperature and sunlight. Ground-level ozone concentrations are highest in the summer and in warmer climates, when sunlight is most intense. Ozone is created when nitrogen oxides and volatile organic compounds interact with sunlight. ${ }^{23}$ Urban heat islands created by intense warming of the ubiquitous impervious surfaces found in densely populated cities further increase ozone levels.

Protecting indoor air quality is just as vital to health as community air quality, although less is generally understood regarding the health impacts of indoor toxins, like volatile organic compounds, formaldehyde, and nitrogen dioxide. ${ }^{24}$ Gas stoves, space heaters, carpeting, paint, particleboard, and other indoor products release toxins that accumulate inside when ventilation is poor. Toxins can also enter buildings from the outside environment and are responsible for serious health effects. Radon, a radioactive gas found in geologic deposits that seeps into buildings through cracks and holes in base-

22 Brunekreef and Holgate 2002

23 Brunekreef and Holgate 2002

24 Jones 1999 
ments and foundations, is the second highest cause of lung cancer after smoking and the primary cause of lung cancer in non-smokers. ${ }^{25}$ Colorless, odorless, and tasteless, radon can easily evade detection. As indoor radon levels fluctuate daily and seasonally, continual in situ monitoring and mitigation are of primary importance to identifying and preventing individual exposure.

Nationally deployed air pollution detection systems focus monitoring on the six criteria air pollutants specified by the U.S. Clean Air Act of 1970 . Monitoring stations report levels of criteria pollutants carbon monoxide, nitrogen dioxide, ground-level ozone, sulfur dioxide, particulate mater, and lead primarily through the 4,000 stations in the State and Local Monitoring (SLAMS) network and 1,080 stations in the National Air Monitoring (NAMS) network. ${ }^{26}$ Individual states determine locations of stations in the SLAMS network and report monitoring data to the EPA annually. National Air Monitoring Stations (NAMS) are specialized SLAMS located predominantly in high-density urban areas to provide more frequent monitoring of ambient air quality where risk of exposure to criteria pollutants is high.

The Air Quality Index (AQI) is the main alerting system for communicating unhealthy air quality levels to the public. The AQI translates concentration levels for five of the six criteria pollutants into an overall scale of daily air quality that ranges from 0 to $500 .{ }^{27}$ Lead concentrations are not utilized in the determination of the AQI. A score of 100 or above on the AQI corresponds to levels of pollution that exceed the EPA's National Ambient Air Quality Standards (NAAQS). ${ }^{28}$ All metropolitan statistical areas with a population greater than 350,000 are required to report daily air quality levels to the public. $^{29}$ Daily AQI levels are communicated through technology and the media. Local news outlets report air quality information through newspapers, radio, and television utilizing guidelines for specific language and phrasing set forth by the EPA. The EPA's AirNow website ${ }^{30}$ allows individuals with Internet access to view current air quality alerts and AQI levels from cities across the United States, as

25 World Health Organization 2009

26 Demerjian 2000

27 Franceschini, Galetto, and Maisano 2005

28 Franceschini, Galetto, and Maisano 2005

29 U.S. Environmental Protection Agency 2006

30 http://www.airnow.gov well as maps of ground-level ozone and airborne particulate levels. Online cameras provide a visible picture of air quality from 61 sites located in 29 states and Washington, DC. The EPA's EnviroFlash system ${ }^{31}$ distributes alerts through email notification, Twitter, and RSS feeds, although cities and agencies must partner with the system in order for data to be available.

Ultimately, whether the issue is hazardous air quality outdoors or indoors, individuals must bear the burden of protecting themselves. This is especially true for exposure on a day-to-day basis. Whereas one would expect that continual air-quality alerts would spark policy interventions in the long term, managing daily exposure to polluted air is a public health responsibility forced upon individuals. Because people possess varying financial resources, degrees of awareness, and abilities to act upon knowledge about air pollution, poor and racial minority populations continue to face exposure to these and other forms of pollution at much higher rates than their more affluent and white counterparts, both within the U.S. and globally. ${ }^{32}$ In this case, the presence of outdoor air-quality sensor and alert systems may create a false sense of equal exposure and a false belief in the effectiveness of technological fixes, which is a situation that may in turn present symbolic barriers to a recognition of persistent environmental dangers and inequalities.

\section{Conclusions}

Electronic systems for sensing and communicating environmental danger could be construed as surveillance systems intended to protect public health. They can collect samples, test those samples for pollutants, translate the presence of pollutants into electronic data, analyze those data against indexes that define what is considered hazardous, and send out alerts that can be acted upon to minimize harmful levels of pollutants or a community's exposure to them. Where ethical problems emerge, however, are in the largely hidden processes of the social construction of risk, responsibility, and the public good. In their current manifestations, these systems probably do allow for an increase in public health over time because they amass data that can be analyzed and acted upon at a later date. In the present, however, the systems are predicated upon

31 http://www.enviroflash.info

32 Bullard 1994, 2005 
a rationality of containment of environmental problems, rather than remediation or prevention of them, and responsibilization of the public for minimizing its exposure to toxins. As with mainstream discussions of other environmental problems, this rationality calls for both individual responsibility and collective blame, ${ }^{33}$ but risk is not shared equally. People who can purchase a variety of products and services to minimize their exposure fare better than those who cannot. People who can regulate their behavior to ensure that they do not go outdoors on days with air-quality alerts or that their children's schools are not in congested urban areas can experience less exposure to pollution than those who cannot. People who happen to live in regions that actively collect, communicate, and act on data about water or air quality may live in safer environments than those who do not.

In the bioethics community, ethical issues are often framed in terms of autonomy instead of trust, and this may have the effect of focusing attention on individual agency to the neglect of social relations. ${ }^{34}$ In the context of the cases discussed here, though, there seems to be an unwarranted trust in technological systems to keep people safe, and an overemphasis on autonomy, in the guise of "choice," to protect oneself through consumption. This orientation obscures power relations and inequalities such that societal ideals of fairness and social justice are further removed from the realm of possibility. In more direct terms, when technical systems for sensing environmental danger are deployed without simultaneous attention to correcting underlying conditions of environmental pollution or social inequality, the systems may do more harm than good; the systems may normalize, and perhaps exacerbate, root problems of contamination and unequal exposure.

\section{References:}

American Water Works Association. 2003. Protecting Our Water: Drinking Water Security in America After 9/11. Denver: American Water Works Association.

Bowker, Geoffrey C., and Susan Leigh Star. 1999. Sorting Things Out: Classification and Its Consequences. Cambridge, MA: MIT Press.

Brunekreef, B. , and S. T. Holgate. 2002. Air Pollution and Health. The Lancet 360:1233-1242.

33 Monahan 2001

34 O'Neill 2002
Bullard, Robert D. 1994. Unequal Protection: Environmental Justice and Communities of Color. San Francisco: Sierra Club Books.

- 2005. The Quest for Environmental Justice: Human Rights and the Politics of Pollution. San Francisco: Sierra Club Books.

Campbell, Chris G., and Adam H. Love. 2008. Monitoring Water Resources for Threats to Water Security. In New Topics in Water Resources Research and Management, edited by H. M. Andreassen. New York: Nova Science Publishers, Inc., 195-234.

Demerjian, K. L. 2000. A Review of National Monitoring Networks in North America. Atmospheric Environment 34 (12-14):1861-1884.

Duhigg, Charles. 2009. Millions in U.S. Drink Dirty Water, Records Show. New York Times, December 8. Available from http://www.nytimes.com/2009/12/08/business/ energyenvironment/08water.htm/?_r=1\&th\&emc =th

Franceschini, F., M. Galetto, and D. Maisano. 2005. A Short Survey on Air Quality Indicators: Properties, Use, and (Mis)use. Management of Environmental Quality 16 (5):490-504.

Graham, Stephen. 2009. When Infrastructure Fails. In Disrupted Cities: When Infrastructure Fails, edited by S. Graham. New York: Routledge, 126.

Guarino, Mark. 2008. Tennessee Spill Revives Coal Ash Controversy Christian Science Monitor, December 31. Available from http://www.csmonitor.com/Environment/2008/1 231/tennessee-spill-revives-coal-ashcontroversy.

Jones, A. P. 1999. Indoor Air Quality and Health. Atmospheric Environment 33 (28):4535-4564.

Knobeloch, L., Salna, B., Hogan, A., Postle, J., \& Anderson, H. . 2000. Blue Babies and NitrateContaminated Well Water. Environmental Health Perspectives 108 (7):675-678.

Miranda, M. L., K. Dohyeong, J. Reiter, M. A. Overstreet Galeano, and P. Maxson. 2009. Environmental Contributors to the Achievement Gap. NeuroToxicology 30:1019-1024.

Monahan, Torin. 2001. Please Increase Your Browser's Memory Partition: Individual Action and Collective Blame in the Hall of Biodiversity. Museum Anthropology 25 (1):41-45.

O'Neill, Onora. 2002. Autonomy and Trust in Bioethics. New York: Cambridge University Press.

Public Citizen. 2004. Homeland Unsecured: The Bush Administration's Hostility to Regulation and 
Ties to Industry Leave America Vulnerable. Washington, D.C.

Ritter, Len, Keith Solomon, Paul Sibley, Ken Hall, Patricia Keen, Gevan Mattu, and Beth Linton. 2002. Sources, Pathways, and Relative Risks of Contaminants in Surface Water and Groundwater: A Perspective Prepared for the Walkerton Inquiry. Journal of Toxicology \& Environmental Health $A 65$ (1): 1-142.

Robertson, L. J., and B. K. Gjerde. 2007. Cryptosporidium Oocysts: Challenging Adversaries? Trends in Parasitology 23 (8):344-347.

Rodriguez-Mozaz, S., M. J. Lopez de Alda, and D. Barcelo. 2006. Biosensors as Useful Tools for Environmental Analysis and Monitoring. Analytical and Bioanalytical Chemistry 386 (4):10251041.

Tiemann, Mary. 2004. Safeguarding the Nation's Drinking Water: EPA and Congressional Actions. Washington, D.C.: Congressional Research Service. Available from http://www.law.umaryland.edu/marshall/crsrepo rts/crsdocuments/RL3129401122004.pdf.

U.S. Environmental Protection Agency. 2003. Water on tap: What you need to know (EPA Publication No. EPA-816-K-03-007). Darby, PA: Diane Publishing.

2. 2006. Guideline for reporting of daily air quality - Air quality index (AQI) (EPA Publication No. EPA-454/B-06-001). Washington, D.C.

- 2009. Drinking water contaminants: List of contaminants and their MCLs. Washington, D.C. Available

from http://www.epa.gov/safewater/contaminants/in dex.html.

World Health Organization. 2009. WHO handbook on indoor radiation: A public health perspective. Geneva: WHO Press. 